\title{
RANCANG BANGUN ALAT UKUR UJI TEKANAN DAN LAJU ALIRAN FLUIDA MENGGUNAKAN POMPA CENTRIFUGAL
}

\author{
Gugun Gunadi ${ }^{1}$ Asep Rachmat ${ }^{2}$, \\ Teknik Mesin, Fakultas Teknik Universitas Majalengka \\ Email: asep18rachmat75@gmail.com
}

\begin{abstract}
ABSTRAK
Prinsip kerja pompa pada dasarnya adalah menurunkan tekanan dalam ruang pompa sisi hisap sehingga akan terjadi perbedaan tekanan antara ruang pompa dengan permukaan fluida yang dihisap, akibatnya fluida akan mengalir ke ruang pompa oleh impeler fluida ini di dorong keluar. Tujuan penelitian ini adalah rancang bangun alat uji tekanan dan laju aliran fluida menggunakan pompa centrifugal. Selain itu juga untuk mengetahui karakteristik pompa pada rangkaian seri dengan cara pemasangan katup pada sisi tekan. Untuk dapat menentukan kurva karakteristik pompa ditambahkan komponen alat ukur berupa pressure geauge sebagai alat ukur tekanan, orifice dan manometer $U$ sebagai alat ukur debit aliran fluida. Kavitasi merupakan faktor yang sering dikaitkan dengan terjadinya kerusakan pada komponen impeler pada pompa centrifugal, maka dalam merancang bangun alat uji ini harus diusahakan agar proses kavitasi dapat dicegah atau diminimalisir sekecil mungkin terhadap kemungkinan terjadinya kavitasi. Untuk dapat menentukan daya pompa yang dibutuhkan dalam alat uji tekanan fluida maka harus dicari nilai head total. Adapun nilai - nilai haed adalah sebagai berikut: head elevasi 0,4 m, head tekan 10,3 m, head laju aliran 0,12 m, haed loses $21,11 \mathrm{~m}$.
\end{abstract}

Kata kunci : rangkaian seri, pompa centrifugal, kavitasi, head.

\section{PENDAHULUAN}

Fluida adalah zat yang berubah bentuk secara kontiniu (terus menerus) bila terkena tegangan geser (fluid mechanics, 1985), hal ini membuktikan hukum pascal bahwa fluida menekan ke segala arah. Selain itu juga ada satu besaran dari fluida yang dapat mencirikan suatu jenis fluida dan membedakannya dengan fluida yang lain. Sifat yang membedakan fluida satu dengan yang lainnya dinamakan dengan massa jenis. Massa jenis tidak hanya berlaku pada fluida saja, tapi berlaku juga pada semua benda tak terkecuali benda tegar. Massa jenis berguna untuk membedakan fluida, karena sifat fluida yang sama namun memiliki masa jenis yang berbeda.

Laju aliran fluida mengalir dari tempat yang tinggi ke tempat yang randah, namun tidak hanya itu saja fluida juga dapat dipindahkan dari suatu tempat bertekanan tinggi menuju ke tempat yang bertekanan lebih rendah.

Pompa merupakan alat untuk memberikan energi mekanis kepada cairan, sedangkan prinsip kerjanya sendiri menghisap dan melakukan penekanan terhadap fluida. Pada sisi hisap (suction) elemen pompa akan menurunkan tekanan dalam ruang pompa sehingga akan terjadi perbedaan tekanan antara ruang pompa dengan permukaan fluida yang dihisap. Akibatnya fluida akan mengalir ke ruang pompa. Oleh elemen pompa fluida ini akan didorong atau diberikan tekanan sehingga fluida akan mengalir ke dalam saluran tekan (discharge) melalui lubang tekan. Proses kerja ini akan berlangsung terus - menerus selama pompa beroperasi.

Karakteristik dari fluida dengan prinsip kerja pompa saling berkaitan, yaitu dimana fluida mampu berpindah dari suatu tempat ke tempat lain dengan catatan kedua tempat tersebut memiliki perbedaan tekanan. Untuk membuat perbedaan itu sendiri dibutuhkan suatu alat yang mampu memberikan tekanan pada ruang tertutup sehingga fluida tersebut mampu terhisap dan berpindah dari suatu tempat ke tempat yang lain.

Sedangkan pompa sentrifugal merupakan alat perpindahan fluida dengna menggunakan 
gaya sentrifugal yang diakibatkan gerak impeller. Seluruh impellar berputar dalam rumah pompa (chasing) dengna kecepatan tinggi, sehingga memberikan percepatan pada fluida yang dialirkan.

Pompa yang dipergunakan sebelumnya harus diketahui karakteristik pada kondisi kerja yang berbeda, dengan demikian dapat ditentukan kemampuan kerja pompa yang digunakan dimana pompa tersebut bisa mencapai efisiensi maksimum. Hal ini perlu dilakukan karena pada kenyataannya pompa sangat mungkin mengalami overload, dengan mengetahui karakteristik pompa merupakan salah satu bentuk proteksi proteksi terhadap pompa yang dipakai.

Teknik pengukuran tekanan secara garis besar dapat di klasifikasikan menjadi tiga kelompok, yakni sebagai berikut:

1. Tekanan yang diberikan oleh kolom fluida (misalnya air raksa) seperti yang terjadi pada manometer.

2. Pengukuran besar deformasi suatu elemen, seperti pada kasus yang terjadi pada tabung Bourdon.

3. Pengukuran kuantitas elektrik.

\section{METODELOGI PENELITIAN}

Studi pustaka merupakan langkah yang dilakukan setelah menentukan pokok permasalahan. Metode ini bertujuan untuk memperoleh teori-teori dasar dan prosedur perancangan yang berkaitan dengan materi yang ditulis.

Survei lapangan dilakukan untuk memperoleh data-data yang diperlukan dalam pembuatan alat uji. Data-data ini bisa berupa data tentang pompa, rangkaian, dan material-material dari setiap komponen.

Study bimbingan yaitu dengan melakukan diskusi tentang topik penelitian ini dengan dosen pembimbing yang telah ditunjuk oleh pihak Fakultas Teknik jurusan Teknik Mesin Universitas Majalengka, dan teman-teman sesama mahasiswa.

Perancangan dimensi pipa, merupakan proses dimana pada tahap ini kita melakukan perancangan pipa yang didalamnya terdapat perkiraan lengkungan, bahan yang digunakan, diameter pipa yang dipakai dan juga panjang pipa yang dibutuhkan.
Penentuan pompa yang digunakan, merupakan hasil keseluruhan proses perhitungan baik itu berupa head loses, head pompa. Selain itu juga pemilihan pompa yang sesuai merupakan penetu kualitet dari alat uji tekanan fluida, karena pompa merupakan instrument utama pada alat uji ini. Proses permesinan juga menentukan ketersedian bahan, kepraktisan dalam melaksanakan proses permesinan, waktu yang dibutuhkan dan dampak yang paling besar adalah agar tercapainya biaya yang seefisien mungkin.

\section{HASIL PENELITIAN \\ 3.1 Rangka}

Rangka merupakan sistem penopang dalam suatu alat. Sistem penopang ini bertindak sebagai bingkai dari elemen - elemen system terkecil dalam alat uji tekanan fluida pada pompa sentrifugal. Disini rangka tersusun atas baja dengan profil siku, profil siku dipilih karana merupakan turunan dari baja strip yang dibangun menjadi bentuk yang lebih rigid. Hal ini mengakibatkan baja jenis ini menjadi lebih kuat bila dibandingkan dengan baja sleb.

Rangka atau frame alat uji yang akan dibuat terlebih dahulu digolongkan kedalam kegunaannya, yang berdasarkan kegunaannya dikelompokan sebagai berikut:

1. Rangka yang memiliki fungsi sebagai dudukan dari motor dan juga pompa centrifugal rangka ini terletak dibagian atats frame.

2. Rangka bagian bawah merupakan tempat dudukan dari bak penampungan air.

3. Kaki- kaki rangka yang memiliki fungsi sebagai penopang dari seluruh elemen dari system alat uji tekanan fluida.

\subsection{Pembebanan Pada Rangka}

Beban rangka terdiri dari beberapa komponen yang bmembebaninya diantaranya:

a. Pompa

b. Motor

c. Bak Penampungan

Berdasarkan pengukuran berat masing masing kompenen pembebanan diperoleh, berat untuk pompa saebesar $5 \mathrm{~kg}$, untuk motor $14 \mathrm{~kg}$, dan bak penampungan dalam keadaan kosong sebesar $15 \mathrm{~kg}$. 
Untuk gaya pembebanan pada rangka adalah.
A. $\mathrm{W}_{\text {Pompa }}=\mathrm{m} \cdot \mathrm{g}$
$=5 \times 10$
B. $\begin{aligned} & =50 \mathrm{~N} \\ \mathrm{~W}_{\text {Pompa }} & =\mathrm{m} \cdot \mathrm{g}\end{aligned}$
$=14 \times 10$
C. $\begin{aligned} & =140 \mathrm{~N} \\ \mathrm{~W}_{\text {Pompa }} & =\mathrm{m} \cdot \mathrm{g}\end{aligned}$
$=15 \times 10$
$=150 \mathrm{~N}$
b. $\Sigma \mathrm{F}_{\mathrm{Y}} \quad=0$
$\mathrm{F}_{\mathrm{AY}}+\mathrm{F}_{\mathrm{BY}}-\mathrm{w}_{\text {bak }}=0$
$\mathrm{F}_{\mathrm{AY}}+\mathrm{F}_{\mathrm{BY}}=\mathrm{w}_{\mathrm{bak}} \times 1,64$
$\mathrm{F}_{\mathrm{AY}}+\mathrm{F}_{\mathrm{BY}}=262,4 \mathrm{~N}$. pers 2
c. $\quad \Sigma \mathrm{M}_{\mathrm{A}}=0$
$\left(1,64 \times \mathrm{F}_{\mathrm{BY}}\right)-\left(0,82 \times \mathrm{w}_{\text {bak }}\right)=0$

$$
\begin{aligned}
& \left(1,64 \times F_{B Y}\right)-(0,82 \times \\
& 262,4)=0 \\
& \left(1,64 F_{B Y}\right)=(0,82 \times \\
& 262,4) \\
& F_{B Y}=\frac{215}{1,64}
\end{aligned}
$$$$
\mathrm{F}_{\mathrm{BY}}=131,2 \mathrm{~N}
$$

\subsection{Gambar Beban yang Terjadi Pada Rangka} batang

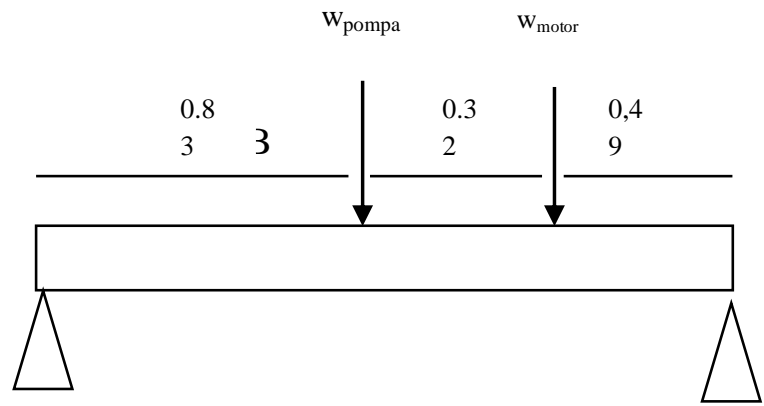

Untuk mencari $\mathrm{F}_{\mathrm{AY}}$ kita tinggal subtitusikan $\mathrm{F}_{\mathrm{BY}}$ kedalam persamaan 2 maka sebagai berikut.

Gambar 1.1 Rangka Serta Bebannya
a. $\Sigma \mathrm{F}_{\mathrm{X}} \quad=0$
$\mathrm{F}_{\mathrm{AX}}+\mathrm{F}_{\mathrm{BX}}=0$
b. $\Sigma \mathrm{F}_{\mathrm{Y}}=0$ dari
$\mathrm{F}_{\mathrm{AY}}+\mathrm{F}_{\mathrm{BY}}-\mathrm{w}_{\text {pompa }}-\mathrm{w}_{\text {motor }}=0$
$\mathrm{F}_{\mathrm{AY}}+\mathrm{F}_{\mathrm{BY}}=\mathrm{w}_{\text {pompa }}+\mathrm{w}_{\text {motor }}$
$\mathrm{F}_{\mathrm{AY}}+\mathrm{F}_{\mathrm{BY}}=50+140$
$\mathrm{F}_{\mathrm{AY}}+\mathrm{F}_{\mathrm{BY}}=190 \mathrm{~N}$

c. $\quad \Sigma \mathrm{M}_{\mathrm{A}} \quad=0$

$\left(1,64 \times \mathrm{F}_{\mathrm{BY}}\right)-\left(0,83 \times \mathrm{w}_{\text {pompa }}\right)-\left(1,15 \times \mathrm{w}_{\text {motor }}\right)$ $=0$

$\mathrm{F}_{\mathrm{AY}}+\mathrm{F}_{\mathrm{BY}}=262,4 \mathrm{~N}$

$\mathrm{F}_{\mathrm{AY}}=262,4 \mathrm{~N}-\mathrm{F}_{\mathrm{BY}}$

0,49

$\mathrm{F}_{\mathrm{AY}}=262,4 \mathrm{~N}-$

\subsection{Daya Pompa}

$131,2 \mathrm{~N}$

$\mathrm{F}_{\mathrm{AY}}=131,2 \mathrm{~N}$

\section{- Haed Statis}

Dengan nilai yang diketahui sebagai berikut:

$$
\begin{aligned}
& \mathrm{Zs}_{\mathrm{s}}=0,9 \mathrm{~m} \\
& \mathrm{Z}_{1}=1,3 \mathrm{~m} \\
& \mathrm{P}_{1}=\mathrm{P}_{2}=1 \mathrm{~atm}
\end{aligned}
$$

(untuk bak terbuka)

$$
\mathrm{V}_{1}=\mathrm{V}_{2}=1,5 \mathrm{~m} / \mathrm{s}
$$

Head Elevasi

(untuk pipa ukuran kecil)

$\left(1,64 \times \mathrm{F}_{\mathrm{BY}}\right)-(0,83 \times 50)-(1,15 \times 140)=0$

$\left(1,64 \mathrm{~F}_{\mathrm{BY}}\right)=(0,83 \times 50)+(1,15 \times 140)$

$1,64 \mathrm{~F}_{\mathrm{BY}} \quad=48,5+161$

$\mathrm{F}_{\mathrm{BY}} \quad=128 \mathrm{~N}$

Untuk mencari $\mathrm{F}_{\mathrm{AY}}$ kita tinggal

subtitusikan $\mathrm{F}_{\mathrm{BY}}$ kedalam persamaan 1 maka sebagai berikut.

$\mathrm{F}_{\mathrm{AY}}+\mathrm{F}_{\mathrm{BY}}=190 \mathrm{~N}$

$\mathrm{F}_{\mathrm{AY}}=190 \mathrm{~N}-\mathrm{F}_{\mathrm{BY}}$

$\mathrm{F}_{\mathrm{AY}}=190 \mathrm{~N}-128 \mathrm{~N}=62 \mathrm{~N}$

Untuk beban yang diberikan oleh bak penampun air dalan keadaan kosong adalah.
a. $\quad \Sigma \mathrm{F}_{\mathrm{X}}$
$\mathrm{F}_{\mathrm{AX}}+\mathrm{F}_{\mathrm{BX}}$
$=0$
$=0$

$$
\begin{aligned}
& \mathrm{H}_{\mathrm{z}}=\mathrm{Zs}-\mathrm{Z}_{1} \\
& \mathrm{H}_{\mathrm{z}}=1,3-0,9 \\
& \mathrm{H}_{\mathrm{z}}=0,4 \mathrm{~m}
\end{aligned}
$$

a. Karana $\mathrm{P}_{1}=\mathrm{P}_{2}$ maka menggunakan

$$
\begin{aligned}
& \text { persar } \frac{P}{\rho \times g} \\
& \mathrm{Hp}=\frac{101325}{1000 \times 9,8} \\
& \mathrm{Hp}=\frac{101325}{9800} \\
& \mathrm{Hp}=10,3 \mathrm{~m}
\end{aligned}
$$


b. Karana $\mathrm{V}_{1}=\mathrm{V}_{2}$ maka menggunakan

0,82

$$
\begin{aligned}
& \text { persamaan. } \\
& \mathrm{H}_{\mathrm{v}}=\frac{v^{2}}{2 \times g} \\
& \mathrm{H}_{\mathrm{v}}=\frac{1,5^{2}}{2 \times 9,8} \\
& \mathrm{H}_{\mathrm{v}}=\frac{2,25}{19,6} \\
& \mathrm{H}_{\mathrm{v}}=0,12 \mathrm{~m}
\end{aligned}
$$

Jadi head statis total adalah.

$$
\begin{aligned}
& \mathrm{H}_{\text {st }}=\mathrm{H}_{\mathrm{z}}+\mathrm{Hp}+\mathrm{H}_{\mathrm{v}} \\
& \mathrm{H}_{\text {st }}=0,5+10,3+0,12 \\
& \mathrm{H}_{\mathrm{st}}=10,92 \mathrm{~m}
\end{aligned}
$$

\section{Haed Loses Saluran Isap}

Kerugian Akibat Gesekan

$\operatorname{Re}=$

$$
\rho \times v \times d_{1}
$$

$\operatorname{Re}=\frac{1000 \times 1,5 \times 0,0381}{0,862 \times 10^{-6}}$

$\operatorname{Re}=\frac{57,15}{0,801 \times 10^{-3}}$

$\operatorname{Re}=71348,31$

Untuk nilai bilangan reynold sebesar 71348,31 termasuk kedalam aliran turbulen. maka untuk mencari koefisian gesek dapat menggunakan persamaan.

$$
\begin{aligned}
& \mathrm{f}=0,02+\frac{0,0005}{d_{1}} \\
& \mathrm{f}=0,02+\frac{0,0005}{0,051} \\
& \mathrm{f}=0,029
\end{aligned}
$$

Untuk mencari nilai head kerugian akibat gesekan pada pipa hisap kita bisa menggunakan prersamaan 2.15 .

$$
\begin{aligned}
& \mathrm{h}_{\mathrm{f}}=0,029 \times \frac{1}{0,051} \times \frac{1,5^{2}}{2.9,8} \\
& \mathrm{~h}_{\mathrm{f}}=f \times \frac{L_{s}}{d_{1}} \times \frac{V_{s}^{2}}{2 \cdot g} \\
& \mathrm{~h}_{\mathrm{f}}=0,065 \mathrm{~m}
\end{aligned}
$$

Kerugian akibat instalasi

Sementara untuk mencari nilai head kerugian akibat instalasi pada pipa hisap kita bisa menggunakan prersamaan 2.16. pada pipa hisap terdapat tiga belokan setandar $90^{\circ}$ maka.

$$
\begin{aligned}
& \mathrm{h}_{\mathrm{m}}=\Sigma \mathrm{n} \cdot \mathrm{k} \frac{1,5^{2}}{2.9,8} \\
& \mathrm{~h}_{\mathrm{m}}=3.30 . \frac{1,5^{2}}{2.9,8}
\end{aligned}
$$

$$
\begin{aligned}
& \mathrm{h}_{\mathrm{m}}=90 \quad \frac{V s^{2}}{2 \cdot g} \\
& \mathrm{~h}_{\mathrm{m}}=10,3 \mathrm{~m}
\end{aligned}
$$

\section{Haed Loses Saluran Tekan}

Kerugian Akibat Gesekan

$$
\begin{aligned}
& \operatorname{Re}=\frac{\rho \times v \times d_{1}}{\mu} \\
& \operatorname{Re}=\frac{1000 \times 1,5 \times 0,049}{0,862 \times 10^{-6}} \\
& \operatorname{Re}=\frac{73,5}{0,801 \times 10^{-3}} \\
& \operatorname{Re}=85266,82
\end{aligned}
$$

Untuk nilai bilangan reynold sebesar 85266,82 termasuk kedalam aliran turbulen. maka untuk mencari koefisian gesek dapat menggunakan persamaan.

$$
\begin{aligned}
& \mathrm{f}=0,02+\frac{0,0005}{d_{1}} \\
& \mathrm{f}=0,02+\frac{0,0005}{0,0381} \\
& \mathrm{f}=0,033
\end{aligned}
$$

Untuk mencari nilai head kerugian akibat gesekan pada pipa hisap kita bisa menggunakan prersamaan 2.15 .

Kerugian akibat instalasi

$$
\begin{aligned}
& \mathrm{h}_{\mathrm{f}}=f \times \frac{L_{s}}{d_{\mathrm{i}}} \times \frac{V_{s}^{2}}{2 \cdot g} \\
& \mathrm{~h}_{\mathrm{f}}=0,033 \times \frac{1}{0,0381} \times \frac{1,5^{2}}{2.9,8} \\
& \mathrm{~h}_{\mathrm{f}}=0,1 \mathrm{~m}
\end{aligned}
$$

Sementara untuk mencari nilai head kerugian akibat instalasi pada pipa hisap kita bisa menggunakan prersamaan 2.16. pada pipa hisap terdapat tiga belokan setandar $90^{\circ}$ maka serta satu katup pengendali jenis globe.

$$
\begin{aligned}
& \mathrm{h}_{\mathrm{m}}=\Sigma \mathrm{n} \cdot \mathrm{k} \quad \frac{1,5^{2}}{2.9,8} \\
& \mathrm{~h}_{\mathrm{m}}=3.30 \frac{1,5^{2}}{2 \cdot 9,8} \\
& \dot{\mathrm{h}}_{\mathrm{m}}=90 \quad \frac{V s^{2}}{2 \cdot g} \\
& \mathrm{~h}_{\mathrm{m}}=10,3 \mathrm{~m}
\end{aligned}
$$
dan untuk katup bola

$$
\begin{aligned}
& \mathrm{h}_{\mathrm{m}}=\Sigma \mathrm{n} \cdot \mathrm{k} \frac{1,5^{2}}{2 \cdot 9,8} \\
& \mathrm{~h}_{\mathrm{m}}=1.3 \cdot \frac{1,5^{2}}{2 \cdot 9,8} \\
& \mathrm{~h}_{\mathrm{m}}=3 . \\
& \mathrm{h}_{\mathrm{m}}=0,34 \mathrm{~m} \\
& \text { jadi } \mathrm{h}_{\mathrm{m}} \text { total adalah. }
\end{aligned}
$$




$$
\begin{aligned}
& \mathrm{h}_{\mathrm{m}}=10,3+0,34 \\
& \mathrm{~h}_{\mathrm{m}}=10,64 \mathrm{~m}
\end{aligned}
$$

\section{Haed Total}

$\mathrm{H}_{\text {tot }}=10,92+0,065+10,3+0,1+10,64$

$\mathrm{H}_{\text {tot }}=32,03 \mathrm{~m}$

Untuk daya pompanya itu sendiri bisa dicari dengan persamaan

$$
\begin{aligned}
& \mathrm{N}=\frac{g \times \rho \times Q \times H \text { tot }}{\eta_{p}} \\
& \mathrm{~N}=\frac{9,8 \times 1000 \times 0,02 \times 32,03}{0,85} \\
& \mathrm{~N}=7385,7 \mathrm{watt}
\end{aligned}
$$

Berdasarkan hasil surpei diperoleh pompa dengan daya $0,75 \mathrm{kw}$.

\section{NPSH pompa}

Ada 2 macam NPSH yaitu NPSHa (Net Positive Suction Head Available) dan NPSHr (Net Positive Suction Head Required).

1. NPSHa adalah nilai NPSH yang ada pada system di mana pompa akan bekerja.

2. NPSHr adalah nilai NPSH spesifik pompa agar bekerja dengan normal, yang diberikan oleh pembuat berdasarkan hasil pengetesan.

$$
\begin{aligned}
\text { NPSHa } & =\mathrm{Pa}-\mathrm{p}-\mathrm{hs}-\mathrm{hi} \\
& =10,3-0.839-0,9-0,608 \\
& =7,953 \mathrm{~m}
\end{aligned}
$$

\section{Pemilihan Pompa}

Berdasarkan hasil perhitungan pompa,maka dipilih tipe pompa sebagai berikut (disesuaikan dengan ketersedian pompa sentrifugal di pompa market) :

Tipe

: Y 802-4

Daya pompa

: $0,75 \mathrm{kw}$.

Head total

: $32,03 \mathrm{~m}$

$\mathrm{NPSHr}$

: $>7,953 \mathrm{~m}$

Kapasitas
1. Titik didih air tidak mutlak $100^{\circ} \mathrm{C}$, tergantung pada tekanan yang terdapat dalam media penampung air yang digunakan. Air yang mendidih mengakibatkan kavitasi di dalam pompa.

2. Diameter pipa masuk harus lebih besar bila dibandingkan dengan pipa keluar.

3. Head pompa terpengaruh oleh beberapa faktor yaitu:

a. Perbedaan tinggi air pada sisi masuk dengan keluar.

b. Diameter pipa yang digunakan.

c. Jenis bak penampungan yang digunakan (keadaan bak dalam keadaan tertuup atau terbuka).

d. Jenis instalasi dan kelengkapan pendukung yang digunakan dalam alat uji.

4. Dalam segi perhitungan tekanan pada pipa keluar alat uji yang dirancang lebih unggul daripada alat uji yang serupa di Untag, karena pada alat uji ini menggunakan bordone tube, sedangkan di untag menggunakan manometer U.

5. Lebih minimalis dibanding dengan alat uji yang telah disurvei.

\section{REFERENSI}

Anis, Samsudin. Buku ajar dasar pompa. Universitas negeri semarang: Semarang. 2008

Achdi, Endang. Panduan praktikum phenomena dasar mesin. Universitas tujuh belas agustus 1945 Cirebon: Cirebon. 2008

Hill, McGraw. fluid mechanics. Erlangga: Jakarta. 1985

Ir. Sularso, MSME, dasar perencanaan dan pemilihan elemen mesin

K. S. Y, Dua. Disain jaringan pipa. Mandar maju: Bandung. 2009

T.G. Hicks, T.W. Edwards. 1996. Teknologi Pemakaian Pompa. Erlangga: Jakarta

\section{KESIMPULAN DAN SARAN}

\section{Kesimpulan}

Dari hasil perancangan alat uji btekanan fluida rangkaian seri dengan menggunakan pompa centrifugal diperoleh kesimpulan bahwa: 